\title{
GABA Type A Receptor Activation in the Allosteric Coagonist Model Framework: Relationship between $\mathrm{EC}_{50}$ and Basal Activity
}

\author{
Gustav Akk, Daniel J. Shin, Allison L. Germann, and Joe Henry Steinbach \\ Department of Anesthesiology (G.A., D.J.S., A.L.G., J.H.S.) and Taylor Family Institute for Innovative Psychiatric Research \\ (G.A., J.H.S.), Washington University School of Medicine, St. Louis, Missouri
}

Received September 8, 2017; accepted November 15, 2017

\section{ABSTRACT}

The concerted transition model for multimeric proteins is a simple formulation for analyzing the behavior of transmitter-gated ion channels. We used the model to examine the relationship between the $\mathrm{EC}_{50}$ for activation of the GABA type $\mathrm{A}\left(\mathrm{GABA}_{\mathrm{A}}\right)$ receptor by the transmitter GABA and basal activity employing concatemeric ternary $\mathrm{GABA}_{\mathrm{A}}$ receptors expressed in Xenopus oocytes. Basal activity, reflecting the receptor function in the absence of the transmitter, can be changed either by mutation to increase constitutive activity or by the addition of a second agonist (acting at a different site) to increase background activity. The model predicts that either mechanism for producing a change in basal activity will result in identical effects on the $\mathrm{EC}_{50}$. We examined receptor activation by GABA while changing the level of basal activity with the allosterically acting anesthetics propofol, pentobarbital, or alfaxalone. We found that the relationship between $\mathrm{EC}_{50}$ and basal activity was well described by the concerted transition model. Changes in the basal activity by gain-of-function mutations also resulted in predictable changes in the $\mathrm{EC}_{50}$. Finally, we altered the number of GABA-binding sites by a mutation and again found that the relationship could be well described by the model. Overall, the results support the idea that interactions between the transmitter GABA and the allosteric agonists propofol, pentobarbital, or alfaxalone can be understood as reflecting additive and independent free energy changes, without assuming any specific interactions.

\section{Introduction}

The concerted transition model for multimeric proteins introduced by Monod, Wyman, and Changeux (the MWC model; Monod et al., 1965) is an elegantly simple formulation for understanding and analyzing the behavior of transmitter-gated ion channels (Del Castillo and Katz, 1957; Karlin, 1967). The model posits that a protein exists in two interconvertible states: active and inactive. It has one or more sets of drug-binding sites. Each site in a set is equivalent to the other sites in that set, while the properties of the sites differ between the states. The model requires only four parameters to describe the macroscopic activation of a receptor.

On the face of it such a simple model seems unlikely to be able to account for the behavior of transmitter-gated channels. However, the behavior of ion channels in the pentameric transmitter-gated ion channel family is rather well described by this model (Karlin, 1967; Jackson, 1986, 1989; Changeux and Edelstein, 1998; Chang and Weiss, 1999; Auerbach, 2012; Forman, 2012; Ehlert, 2014b; Gupta et al., 2017). For the $\gamma$-aminobutyric acid type $\mathrm{A}\left(\mathrm{GABA}_{\mathrm{A}}\right)$ receptor, this area of study was pioneered by Chang and Weiss (1999), who demonstrated that the macroscopic properties of activation of $\mathrm{GABA}_{\mathrm{A}}$ receptors by the transmitter could be well described by the MWC model.

This work was supported by the National Institutes of Health National Institute of General Medical Sciences [Grant R01GM108580]; and funds from the Taylor Family Institute for Innovative Psychiatric Research

https://doi.org/10.1124/mol.117.110569.
Further work by Forman and collaborators (Rüsch et al., 2004; Rüsch and Forman, 2005; Ruesch et al., 2012) demonstrated that the actions of several potentiating drugs on the $\mathrm{GABA}_{\mathrm{A}}$ receptor could be understood in terms of this model without additional, ad hoc, interactions.

We examined the application of the concerted transition model to the behavior of the $\mathrm{GABA}_{\mathrm{A}}$ receptor in terms of the ability of allosteric agents to potentiate activation by GABA. As emphasized by Forman (Ruesch et al., 2012) the ability of a drug to potentiate can be described in terms of its ability to decrease the concentration of agonist required to elicit a halfmaximal response $\left(\mathrm{EC}_{50}\right)$ as well as its ability to increase the response to a given concentration of the agonist. We used examples of three types of intravenous anesthetics as potentiator (propofol, the barbiturate pentobarbital, and the anesthetic steroid alfaxalone) to determine whether the model accurately predicts the shift in $\mathrm{EC}_{50}$ for $\mathrm{GABA}$. We also altered the intrinsic probability of being open for the receptor and the number of binding sites for GABA by mutations. Our results indicate that the model is remarkably successful at accounting for the ability of allosteric agonists or receptor mutations to alter activation by the transmitter.

In particular, the results suggest that the actions of these combinations of agonists do not require any specific interactions between the agents (e.g., changes in affinity) but reflect coupling via additive changes in the free energy as the result of interactions between the receptor and the agonists. In more practical terms, the change in $\mathrm{EC}_{50}$ value for agonist $\mathrm{A}$ produced

ABBREVIATIONS: DMSO, dimethylsulfoxide; $\mathrm{GABA}_{\mathrm{A}}$ receptor, $\gamma$-aminobutyric acid type A receptor; MSD, mean squared difference; MWC model, Monod, Wyman, and Changeux model; $P\{$ open\}, probability of being open. 
by any concentration of agonist $B$ can be predicted from the direct response to $\mathrm{B}$ and the parameters describing activation by $\mathrm{A}$ in the absence of other activating agents. Similarly, the effects of mutations that alter constitutive activity of the receptor or the number of sites for an agonist can be predicted.

\section{Materials and Methods}

Constructs and Expression. The experiments were conducted on rat $\alpha 1 \beta 2 \gamma 2 \mathrm{~L} \mathrm{GABA}_{\mathrm{A}}$ receptors formed by assembly of two concatemeric constructs comprising $\beta 2-\alpha 1-\gamma 2 \mathrm{~L}$ (abbreviated as $\beta \alpha \gamma$ ) and $\beta 2-\alpha 1(\beta \alpha)$ subunits. To simplify the presentation, we will refer to "wild-type" $\beta \alpha \gamma+\beta \alpha$ receptors when the concatemers had no mutations present, even though the receptors per se are clearly not wild type. The use of concatemeric receptors enabled the generation of receptors containing controlled numbers and positions of mutations. The generation and functional characterization of these constructs have been reported previously elsewhere (Bracamontes and Steinbach, 2009; Bracamontes et al., 2011).

The functional properties of the wild-type receptors comprising concatemeric constructs and free subunits are quite similar even at the single-channel level (Akk et al., 2009), although most studies have indicated a $\sim 2$-fold right shift in the GABA concentration-response relationships (Baumann et al., 2002; Akk et al., 2009; Bracamontes et al., 2011). The reason for the right-shifted concentration-response relationship is not entirely clear, but a previous single-channel study found that subunit linkage can affect receptor affinity to the transmitter (Akk et al., 2009).

The concatemers are not degraded when expressed in Xenopus oocytes (Bracamontes et al., 2011). Furthermore, receptors activated by $5-\mu \mathrm{M}$ GABA (approximately $\mathrm{EC}_{7}$ ) were potentiated to $308 \% \pm 32 \%$ $(n=6)$ of control in the presence of $1 \mu \mathrm{M}$ diazepam, indicating that the $\gamma 2 \mathrm{~L}$ subunit was incorporated. Introduction of reporter mutations into the $\alpha 1$ subunit (see Results) indicated that the assembled receptors incorporate both concatemers. Point mutations [ $\alpha 1$ (L263S), $\beta 2$ (Y205S), $\beta 2(\mathrm{Y} 143 \mathrm{~W})]$ were generated using QuikChange (Agilent Technologies, Santa Clara, CA). The cDNAs were subcloned into the pcDNA3 vector in the T7 orientation. The cRNAs were produced using mMessage mMachine (Ambion, Austin, TX) after linearization by digestion with Xba I (NEB Laboratories, Ipswich, MA).

Oocytes from the African clawed frog (Xenopus laevis) were used for expression of the receptors. The frogs were purchased from Xenopus 1 (Dexter, MI), and they were housed and cared for in a Washington University animal care facility under the supervision of the Washington University Division of Comparative Medicine. Harvesting of oocytes was conducted in accordance with the Guide for the Care and Use of Laboratory Animals as adopted and promulgated by the National Institutes of Health. The protocol was approved by the Animal Studies Committee of Washington University in St. Louis (Approval No. 20170071).

Oocytes were injected with a total of $20 \mathrm{ng}$ cRNA in a final volume of $30-70 \mathrm{nl}$ of nuclease-free water (Thermo Fisher Scientific, Waltham, MA) at the ratio of $1: 1(\beta \alpha \gamma: \beta \alpha)$. After injection, the oocytes were incubated in ND96 buffer ( $96 \mathrm{mM} \mathrm{NaCl}, 2 \mathrm{mM} \mathrm{KCl}, 1.8 \mathrm{mM} \mathrm{CaCl}_{2}$, $1 \mathrm{mM} \mathrm{MgCl}_{2}, 2.5 \mathrm{mM}$ Na pyruvate, $100 \mathrm{U} / \mathrm{ml}$ penicillin, $100 \mu \mathrm{g} / \mathrm{ml}$ streptomycin, $50 \mu \mathrm{g} / \mathrm{ml}$ gentamycin, $5 \mathrm{mM}$ HEPES; $\mathrm{pH} 7.4$ ) at $16^{\circ} \mathrm{C}$, and they were used in electrophysiologic recordings within 24 to 72 hours.

Electrophysiology. The experiments were conducted using standard two-electrode voltage clamp. Voltage and current electrodes were borosilicate glass capillaries (G120F-4, o.d. $1.20 \mathrm{~mm}$, i.d. $0.69 \mathrm{~mm}$; Warner Instruments, Hamden, CT). When filled with $3 \mathrm{M} \mathrm{KCl}$ the pipette resistance was less than $1 \mathrm{M} \Omega$. The oocytes were clamped at $-60 \mathrm{mV}$. The chamber (RC-1Z; Warner Instruments) was perfused with bath solution $(92.5 \mathrm{mM} \mathrm{NaCl}, 2.5 \mathrm{mM} \mathrm{KCl}, 1 \mathrm{mM} \mathrm{MgCl} 2,10 \mathrm{mM}$ HEPES; $\mathrm{pH}$ 7.4) at approximately $8 \mathrm{ml} \cdot \mathrm{min}^{-1}$. Solutions were gravityapplied from $30-\mathrm{ml}$ glass syringes with glass Luer slips via Teflon tubing to reduce adsorption. The application of agonists was typically 20 to 60 seconds long, followed by washout in bath solution (up to 5 minutes) until recovery. The solutions were switched manually. Test applications (e.g., to a saturating concentration of GABA) were performed at the beginning and end of recordings from each cell to verify the overall stability of the responses.

The currents were amplified with an OC-725C (Warner Instruments) or Axoclamp 900A amplifier (Molecular Devices, Sunnyvale, CA) filtered at $40 \mathrm{~Hz}$ and digitized with a Digidata 1200 or 1320 series digitizer (Molecular Devices) at $100 \mathrm{~Hz}$, and recorded using pClamp software (Molecular Devices). Current traces were analyzed with Clampfit (Molecular Devices) to determine the peak amplitude of the response measured from the preceding baseline current.

Analysis of Current Responses. The analysis of electrophysiologic recordings was aimed at determining the concentration-response properties and the level of basal activity for individual receptor-agonist combinations. Two principal types of concentration-response experiments were conducted. In the first type, the oocytes were exposed to a range of concentrations of GABA. The concentration-response curves were fitted for each cell separately with the following equation:

$$
Y=Y_{\max } \times \frac{[\mathrm{GABA}]^{n_{\mathrm{H}}}}{[\mathrm{GABA}]^{n_{\mathrm{H}}}+\mathrm{EC}_{50^{n_{\mathrm{H}}}}}
$$

where $\mathrm{EC}_{50}$ is the concentration of GABA producing a half-maximal effect, $n_{\mathrm{H}}$ is the Hill slope, and $Y_{\max }$ is the high-concentration asymptote.

In the second case, oocytes were exposed to a range of concentrations of GABA in the presence of a fixed, low concentration of a secondary activator, termed the "background" drug (propofol, alfaxalone, or pentobarbital). The concentration-response curves were fitted with the following equation:

$$
Y=Y_{\min }+\left(Y_{\max }-Y_{\min }\right) \times \frac{[\mathrm{GABA}]^{n_{\mathrm{H}}}}{[\mathrm{GABA}]^{n_{\mathrm{H}}}+\mathrm{EC}_{50^{n_{\mathrm{H}}}}}
$$

where $\mathrm{EC}_{50}$ is the concentration of GABA producing a half-maximal effect, $n_{\mathrm{H}}$ is the Hill slope, and $Y_{\min }$ and $Y_{\max }$ are the low- and highconcentration asymptotes, respectively. The fitted $Y_{\min }$ was typically indistinguishable from the response to the background activator.

Curve fitting was conducted using the NFIT software (University of Texas Medical Branch at Galveston, Galveston, TX). The results are reported as mean \pm S.E.M. (number of cells).

Converting Membrane Current to Probability of Being Open. We adopted the procedures developed by Forman (Forman, 2012; Forman and Stewart, 2012; Eaton et al., 2016) to establish a scale for converting current responses to an estimated probability of being open $[P\{$ open $\}]$. The maximal response possible from a given cell $\left(I_{\max }\right)$ was estimated by applying a saturating concentration of GABA plus a potentiator that gave the largest measured response. In the present experiments this was accomplished using $3 \mathrm{mM}$ GABA plus $100 \mu \mathrm{M}$ pentobarbital. This response was assumed to be equivalent to a $P$ \{open\} of 1 (Ziemba and Forman, 2016). The probability of being open in the absence of agonist was estimated by blocking any constitutive current using picrotoxin [300 $\mu \mathrm{M}$ for the wild-type concatemeric receptor or $500 \mu \mathrm{M}$ for receptors containing the $\alpha 1$ (L263S) mutation]. The current level in the presence of picrotoxin was assumed to correspond to a $P$ \{open $\}$ of 0 .

The GABA concentration-response relationship in the wild-type $\beta \alpha \gamma+\beta \alpha$ receptor was converted to units of $P$ \{open\} by normalization to the response to $3 \mathrm{mM}$ GABA in that cell, and scaling by the estimated $\mathrm{P}\{$ open\} for the response to $3 \mathrm{mM}$ GABA:

$$
P\{\text { open, }[\mathrm{GABA}]\}=\frac{I_{\mathrm{GABA}}-I_{\mathrm{PTX}}}{I_{3000 \mathrm{G}}-I_{\mathrm{PTX}}} \times \frac{I_{3000 \mathrm{G}}-I_{\mathrm{PTX}}}{I_{\mathrm{max}}-I_{\mathrm{PTX}}}
$$

where $P$ \{open, [GABA] $\}$ is the probability of being open in the presence of a given concentration of GABA, $I_{\mathrm{GABA}}$ is the current response to that concentration of GABA, $I_{3000 \mathrm{G}}$ is the current response to $3 \mathrm{mM}$ GABA, 
and $\mathrm{I}_{\mathrm{PTX}}$ is the amplitude of the outward current in the presence of picrotoxin. The term $\left(I_{3000 \mathrm{G}}-I_{\mathrm{PTX}}\right) /\left(I_{\max }-I_{\mathrm{PTX}}\right)$, i.e., the scaling factor providing the estimated $P$ \{open\} for the response to $3 \mathrm{mM}$ GABA, was determined separately in five cells.

Materials, Drugs, and Solutions. Most chemicals, including GABA, pentobarbital and the salts used to prepare buffers were purchased from Sigma-Aldrich (St. Louis, MO). Propofol was from MP Biomedicals (Solon, OH), and alphaxalone from Sigma-Aldrich or Tocris (Bio-Techne, Minneapolis, MN).

Stock solutions of GABA $(500 \mathrm{mM})$ and pentobarbital $(5 \mathrm{mM})$ were made in bath solution. Stock solutions of propofol $(200 \mathrm{mM})$ and alphaxalone $(10 \mathrm{mM})$ were made in dimethylsulfoxide (DMSO). Aliquots of GABA stock were kept frozen at $-20^{\circ} \mathrm{C}$ then thawed and diluted as needed on the day of the experiment. Stock solutions of pentobarbital, propofol, and alphaxalone were stored at room temperature.

The maximal DMSO concentration in final working solutions was $0.5 \%$. This concentration of DMSO is without effect on holding current or the peak amplitude of the response to an $\mathrm{EC}_{50}$ concentration of GABA from oocytes expressing $\alpha 1 \beta 3 \gamma 2 \mathrm{~L}$ receptors (Germann et al., 2016).

\section{Results}

Description of the Model. The application of the concerted transition model to the $\mathrm{GABA}_{\mathrm{A}}$ receptor was described previously elsewhere (Chang and Weiss, 1999; Forman, 2012). We used this model (Fig. 1) to explore the relationship between the concentration of GABA producing a halfmaximal response $\left(\mathrm{EC}_{50}\right)$, the gating equilibrium constant for unliganded receptors (L), and the number of binding sites for the transmitter $(N)$.

The state function for the receptor-the probability that a receptor is in the open state or, on a macroscopic level, the fraction of receptors that are in the open state-is given by the following equation:

$$
P\{\text { open }\}=\frac{1}{1+\mathrm{L} \times\left[\frac{1+[\mathrm{A}] / K_{\mathrm{A}}}{1+[\mathrm{A}] / c_{\mathrm{A}} K_{\mathrm{A}}}\right]^{N_{\mathrm{A}}}}
$$

where $\mathrm{A}$ is an agonist, $K_{\mathrm{A}}$ is the equilibrium dissociation constant for the agonist when the receptor is in the closed state, and $N_{\mathrm{A}}$ is the number of sites for $\mathrm{A}$. The parameter $\mathrm{L}$ is the ratio of the fraction of channels in the closed state to the fraction of channels in the open state in the absence of agonist, and it reflects the difference in the free energies of the closed and open states in the absence of an agonist. A small value for $\mathrm{L}$ indicates that the channels activate readily even in the absence of an agonist. The parameter $c_{\mathrm{A}}$ is the ratio of the equilibrium dissociation constants for binding in the open state to that in the closed state, reflecting the selectivity of the agonist between the two states. Agonists, by definition, bind more tightly to the active state of the receptor; hence, the value for $c_{\mathrm{A}}$ is $<1$. In the absence of an agonist the probability of being open is $P$ \{open, $\min \}=1 /(1+\mathrm{L})$; the maximal probability of being active in the presence of a saturating concentration of A is $P\{$ open, $\max \}=1 /\left(1+\mathrm{L} c_{\mathrm{A}}{ }^{N_{\mathrm{A}}}\right)$. The "stabilization energy" contributed by the binding of an agonist when all sites are occupied is $N_{\mathrm{A}} \mathrm{RT} \times \ln \left(c_{\mathrm{A}}\right)$, whereas the free energy difference between the fully liganded closed and fully liganded open states is $N_{\mathrm{A}} \mathrm{RT} \times \ln \left(\mathrm{L} c_{\mathrm{A}}\right)$.

Interactions among Agonists Are Mediated through Change in $\mathbf{L}$. If a second activator (B) is present that does not bind to the same site as A, eq. 4 becomes

$$
P\{\text { open }\}=\frac{1}{1+\mathrm{L} \times\left[\frac{1+[\mathrm{A}] / K_{\mathrm{A}}}{1+[\mathrm{A}] / c_{\mathrm{A}} K_{\mathrm{A}}}\right]^{N_{\mathrm{A}}}\left[\frac{1+[\mathrm{B}] / K_{\mathrm{B}}}{1+[\mathrm{B}] / c_{\mathrm{B}} K_{\mathrm{B}}}\right]^{N_{\mathrm{B}}}}
$$

where $K_{\mathrm{B}}$ is the dissociation constant for agonist B binding to its site when the receptor is in the closed state, $c_{\mathrm{B}}$ is the ratio of the dissociation constants for binding of $\mathrm{B}$ in the open to that in the closed state, $N_{\mathrm{B}}$ is the number of sites for $\mathrm{B}$, and other terms are as defined earlier. The case in which both compounds (A and B) bind to the same site is considered by Karlin (1967).

Inspection of eq. 5 indicates that in the presence of a constant concentration of agonist $\mathrm{B}$ the effects of $\mathrm{B}$ on responses to

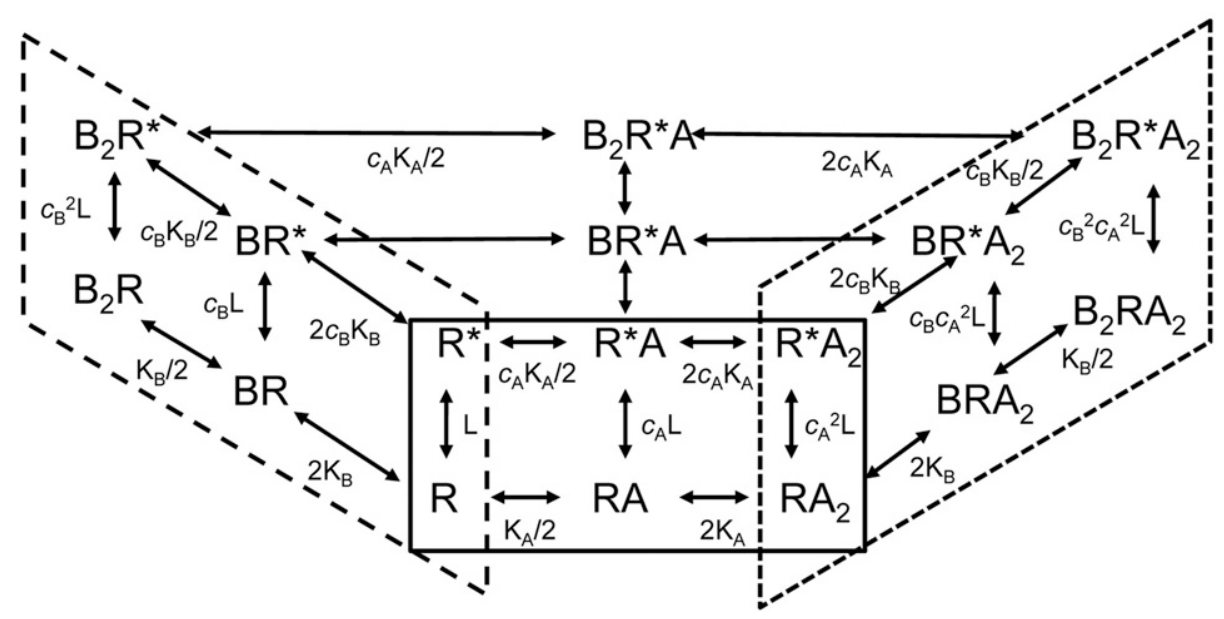

Fig. 1. Partial state diagram for two drugs (A and B, each with two sites) acting on a receptor following the concerted transition scheme. Closed receptor states $(R)$ occupy the plane at the bottom (note that some states are obscured such as $B_{2} R A$ ) while open states $\left(R^{*}\right)$ occupy the plane at the top. The diagram is distorted to show states with only agonist A bound (solid line box at front), only agonist $\mathrm{B}$ bound (long dashed line box at left), and some states with both agonists bound (short dash box at right). In the absence of both $A$ and $B$ the receptor activates constitutively with $L=R / R^{*}$. The value of the parameter L is a property of the receptor, not of any agonist. Agonist A binds to its site with dissociation constant $K_{\mathrm{A}}$ on the closed receptor and $K_{\mathrm{A}} *$ on the open receptor, with $c_{\mathrm{A}}=K_{\mathrm{A}} * / K_{\mathrm{A}}$. Note that the presence of bound $\mathrm{B}$ does not affect binding of A nor vice versa. The equilibrium between $\mathrm{R}$ and $\mathrm{R}^{*}$ states is determined by the respective values for $c$, as dictated by detailed mass action in the coupled cycles (e.g., $\mathrm{B}_{2} \mathrm{R} / \mathrm{B}_{2} \mathrm{R}^{*}=c_{\mathrm{B}}{ }^{2} \mathrm{~L}$ and $\mathrm{B}_{2} \mathrm{RA} \mathrm{A}_{2} / \mathrm{B}_{2} \mathrm{R}^{*} \mathrm{~A}_{2}=c_{\mathrm{B}}{ }^{2} c_{\mathrm{A}}{ }^{2} \mathrm{~L}$ ). 
agonist A can be understood simply as a change in the apparent value of $\mathrm{L}$ :

$$
\mathrm{L}^{*}=\mathrm{L} \times\left[\frac{1+[\mathrm{B}] / K_{\mathrm{B}}}{1+[\mathrm{B}] / c_{\mathrm{B}} K_{\mathrm{B}}}\right]^{N_{\mathrm{B}}}
$$

where $\mathrm{L}^{*}$ is the modified $\mathrm{L}$ reflecting a change due to the presence of agonist B. This equation explains the relationship between activation by one compound and that compound's ability to potentiate responses to another. This relationship has been investigated and supported for the $\mathrm{GABA}_{\mathrm{A}}$ receptor by Forman and collaborators (Rüsch et al., 2004; Ruesch et al., 2012).

The Relationship between the $\mathbf{E C}_{50}$ for an Agonist and $\mathbf{L}$. The $\mathrm{EC}_{50}$ is the concentration of agonist that produces a response halfway between the baseline current in the absence of the agonist and the maximal response the agonist can generate. In the MWC model, the $\mathrm{EC}_{50}$ for activation of a receptor by an agonist normalized to its affinity to the compound is given by (Karlin, 1967):

$$
\mathrm{EC}_{50} /(c K)=\frac{\left(2+\mathrm{L}+\mathrm{L} c^{N}\right)^{1 / N}-\left(1+c^{N}+2 \mathrm{~L} c^{N}\right)^{1 / N}}{\left(1+c^{N}+2 \mathrm{~L} c^{N}\right)^{1 / N}-c\left(2+\mathrm{L}+\mathrm{L} c^{N}\right)^{1 / N}}
$$

The relationship between $\mathrm{EC}_{50}$ and $\mathrm{L}$ for values of $N$ of 1,2 , and 5 (with $c=0.01$ ) is shown in Fig. 2A. The predictions cover a large range of values for $L$ to illustrate that the value for $\mathrm{EC}_{50}$ shows asymptotes at both low and high values of $\mathrm{L}$.

Chang and Weiss (1999) were the first to demonstrate experimentally for $\mathrm{GABA}_{\mathrm{A}}$ receptors that the relationship shows an asymptote when $\mathrm{L}<1$. Edelstein and Changeux (1996) provided expressions for the values of these asymptotes. As $\mathrm{L}$ approaches $0, \mathrm{EC}_{50}$ approaches $c K\left(2^{1 / N}-1\right)$, and as $\mathrm{L}$ approaches infinity, $\mathrm{EC}_{50}$ approaches $K /\left(2^{1 / N}-1\right)$. Inspection of the relationship in Fig. 2A indicates that the curvature toward the asymptotes becomes marked when $\mathrm{L}<1$ and $\mathrm{L}>1 / c^{N}$. When $1 / c^{N}$ is much larger than 1 , the asymptotes are well separated, and the slope of the relationship between $\log \left(\mathrm{EC}_{50}\right)$ and $\log (\mathrm{L})$ approaches $1 / N$, as first pointed out by Karlin (1967). The approximation is good over a particularly wide range for $N=2$.

Figure $2 \mathrm{~B}$ shows plots of the predicted $\mathrm{EC}_{50}$ against $\mathrm{L}$ for $N$ values of 1,2 , and 5 to indicate the nature of the relationships that might be experimentally obtained for an intermediate value of $c(c=0.01)$ and values of $L$ from 1 to 100,000. Figure 2, $\mathrm{C}$ and $\mathrm{D}$, shows similar plots for $N$ values of 2 and 5 , now calculated with three values for $c$ that cover most of the range of values reported for agonists acting on the $\mathrm{GABA}_{\mathrm{A}}$ receptor ( $c=0.1,0.01$, and 0.001). In these plots the slopes of the predicted relationships are shown, estimated from the linear regression of $\log \left(\mathrm{EC}_{50}\right)$ on $\log (\mathrm{L})$ over the range of values of $\mathrm{L}$ where the relationship appeared linear (indicated in the figures). The fitted slope is larger than $1 / N$ when $N$ is greater than 1 , and the deviation increases as $N$ increases. The reason for this difference can be seen in Fig. 2A and arises because the predicted values for the $\mathrm{EC}_{50}$ initially lie below the line indicating $\mathrm{L}^{1 / N}$, so the slope for $\mathrm{L}$ values not that much larger than 1 is actually greater than $1 / N$.

The logarithmic regression slopes fitted to the predicted values are shown in Table 1 . The slopes were fitted over the linear portion of the relationship (indicated in the table) and demonstrate that the $1 / N$ relationship is most accurate in the case that $N=2$, but in general for $N>1$ the actual slopes are larger than $1 / N$.

The values of $L$ for wild-type $\mathrm{GABA}_{\mathrm{A}}$ receptors reported in the literature are in the range of 1000-100,000 (Chang and Weiss, 1999; Ziemba and Forman, 2016), and for receptors with gain-of-function mutations $\mathrm{L}$ can be less than 1 (Chang and Weiss, 1999). The reported values of $c$ range from about 0.001 for a strong agonist such as GABA (see below) to about 0.5 for a weaker agonist such as diazepam (Chang and Weiss, 1999; Rüsch et al., 2004; Rüsch and Forman, 2005).
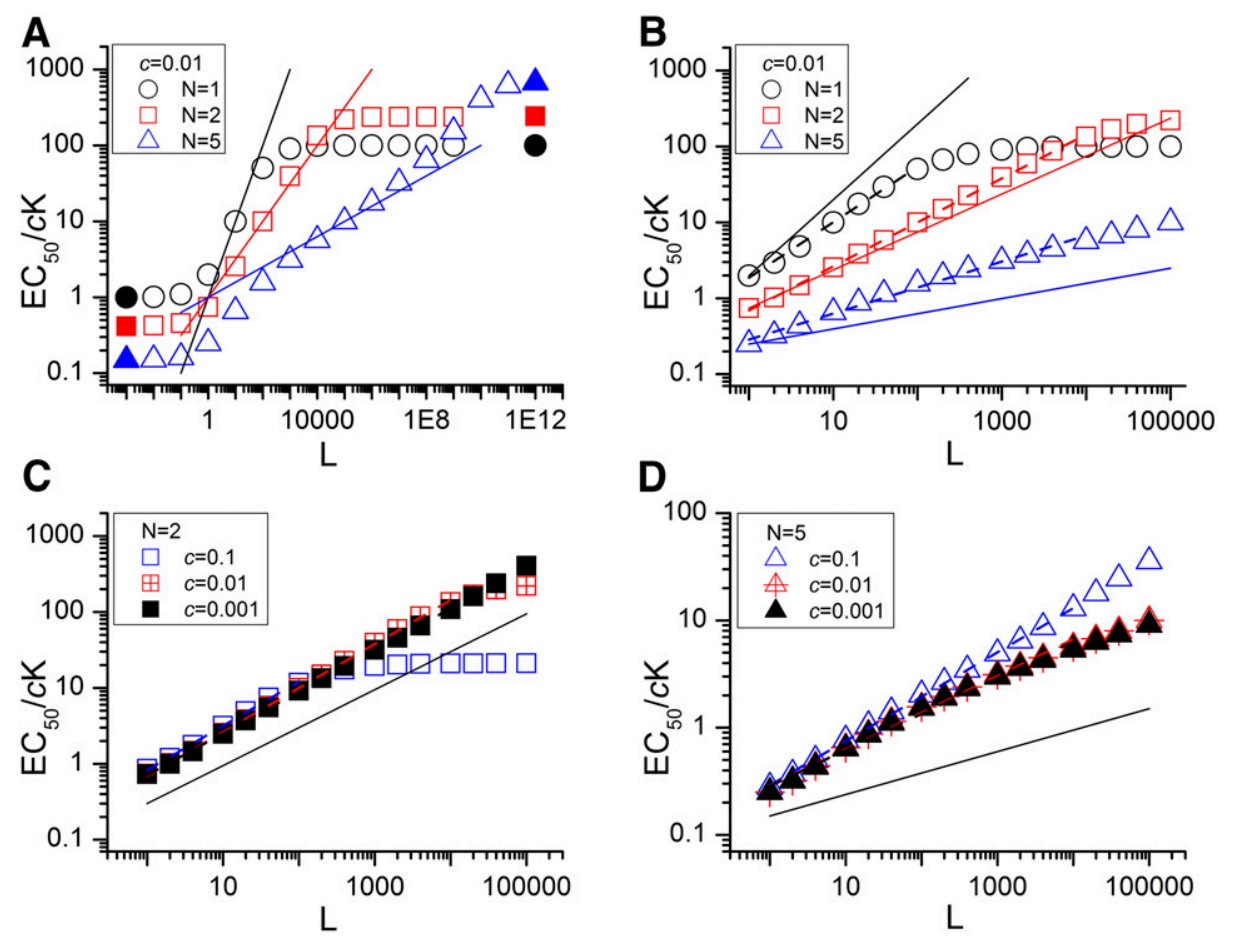

Fig. 2. The theoretical relationship between normalized $\mathrm{EC}_{50}$ and $\mathrm{L}$. The figure shows the predicted $\mathrm{EC}_{50}$ plotted logarithmically against the value for $\mathrm{L}$. The values for $\mathrm{EC}_{50}$ are normalized to the dissociation constant for the open state. (A) Relationships for $N$ values of $1(\bigcirc), 2(\square)$, and $5(\triangle)$ for $c=0.01$ over a wide range of values for $\mathrm{L}\left(10^{-2}\right.$ to $\left.10^{12}\right)$. The filled symbols show the predicted asymptotic values (see Results). The lines show slopes of $1 / N$. (B) Same as $A$ but over a range of $\mathrm{L}$ values previously reported for the $\mathrm{GABA}_{\mathrm{A}}$ receptor to illustrate results that might be obtained experimentally. The dashed lines show the linear regression on the logarithmically transformed data; the slopes of the regression lines are 0.75 for $N=1,0.58$ for $N=2$ and 0.37 for $N=5$. The solid lines show slopes of $1 / N$. (C and D) Relationships between predicted $\mathrm{EC}_{50}$ and $\mathrm{L}$ for $N=2(\mathrm{C})$ and $N=5$ (D). Three values for $c$ were used-c $-0.1, c=0.01$, and $c=0.001$-to cover the range appropriate for the $\mathrm{GABA}_{\mathrm{A}}$ receptor ( $\mathrm{L}=1$ to 100,000 ). The solid lines show lines with slope of $1 / N$. Table 1 provides slopes for the linear regression on the logarithmically transformed data for a number of combinations for $N, \mathrm{~L}$, and $c$. 


\section{TABLE 1}

Slope of the relationship between $\log (\mathrm{L})$ and predicted $\log \left(\mathrm{EC}_{50}\right)$ Results of linear regression of the value for $\log \left(\mathrm{EC}_{50}\right)$ on $\log (\mathrm{L})$ (third column), for various values of $N$ (first column) and $c$ (second column). The values were chosen to cover the range of proposed number of sites, and reported values for $c$ for agonists acting on the $\mathrm{GABA}_{\mathrm{A}}$ receptor. The predictions were fit over a range of values for $\mathrm{L}$ that visually appear largely linear, as indicated in the fifth column. The fourth column gives the value of $1 / N$.

\begin{tabular}{llllc}
\hline$N$ & \multicolumn{1}{c}{$c$} & Slope & $1 / N$ & $\begin{array}{c}\text { Range } \\
\text { of } L\end{array}$ \\
\hline 1 & 0.1 & 0.42 & 1.00 & $1-10$ \\
1 & 0.01 & 0.75 & 1.00 & $1-40$ \\
1 & 0.001 & 0.86 & 1.00 & $1-200$ \\
2 & 0.1 & 0.59 & 0.50 & $1-100$ \\
2 & 0.01 & 0.58 & 0.50 & $1-1000$ \\
2 & 0.001 & 0.55 & 0.50 & $1-1000$ \\
3 & 0.1 & 0.55 & 0.33 & $1-400$ \\
3 & 0.01 & 0.45 & 0.33 & $1-2000$ \\
3 & 0.001 & 0.44 & 0.33 & $1-2000$ \\
4 & 0.1 & 0.48 & 0.25 & $1-2000$ \\
4 & 0.01 & 0.39 & 0.25 & $1-2000$ \\
4 & 0.001 & 0.39 & 0.25 & $1-2000$ \\
5 & 0.1 & 0.42 & 0.20 & $1-1000$ \\
5 & 0.01 & 0.37 & 0.20 & $1-1000$ \\
5 & 0.001 & 0.37 & 0.20 & $1-1000$ \\
\hline
\end{tabular}

Summary. In summary, there are two major points from this introduction.

1. Interactions between activators in the context of the concerted transition model (Fig. 1) can be understood as resulting from modification of $\mathrm{L}$. An important caveat is that the compounds do not bind to the same site(s) on the receptor.

2. For a given value of $\mathrm{L}$, the $\mathrm{EC}_{50}$ value, and in fact the whole concentration-response relationship, for agonist $\mathrm{X}$ can be predicted given values for $c_{\mathrm{X}}, K_{\mathrm{X}}$, and $N_{\mathrm{X}}$.

Relating the Model to Experimental Data: Activation of the Wild-Type $\boldsymbol{\beta} \alpha \boldsymbol{\gamma}+\boldsymbol{\beta} \boldsymbol{\alpha}$ Receptor. Oocytes expressing wild-type $\beta \alpha \gamma+\beta \alpha \mathrm{GABA}_{\mathrm{A}}$ receptors were exposed to $1-1000$ $\mu \mathrm{M}$ GABA. The concentration-response curves were fitted to eq. 1 . The mean values of the fit were $\mathrm{EC}_{50, \mathrm{GABA}}=34 \pm 8 \mu \mathrm{M}$ $(n=5$ cells $)$ and $n_{\mathrm{H}, \mathrm{GABA}}=1.38 \pm 0.07$ (Fig. $\left.3 \mathrm{~A}\right)$.

The peak response in the presence of $3 \mathrm{mM}$ GABA plus $100 \mu \mathrm{M}$ pentobarbital was $1.08 \pm 0.02$ times the response to $3 \mathrm{mM}$ GABA alone $(n=7, P=0.01$ that the responses are equal), indicating that $P$ \{open, GABA $\max \}=0.93 \pm 0.02$. This estimate is in agreement with previous $P$ \{open, GABA max\} estimates in single-channel and whole-cell studies (Steinbach and Akk, 2001; Lema and Auerbach, 2006; Ruesch et al., 2012; Hernandez et al., 2017). Application of $300 \mu \mathrm{M}$ picrotoxin resulted in outward current, reflecting block of constitutively active receptors (Fig. 3B). We estimated $\mathrm{L}$ for the wild-type $\beta \alpha \gamma+\beta \alpha$ receptor from the relationship $(1-P$ open, constitutive $\} / P$ (open, constitutive $\}$ yielding $8101 \pm 1238$ $(n=15)$. This value is close to the geometric middle of the range of estimates for $\mathrm{L}(1000-100,000)$ for $\mathrm{GABA}_{\mathrm{A}}$ receptors composed of free wild-type subunits (Chang and Weiss, 1999; Ziemba and Forman, 2016). We assumed for the rest of this analysis that the best estimate for the value of $L$ was close to the directly measured value and set $\mathrm{L}_{\mathrm{WT}}=9000$ for receptors composed of wild-type concatemers in the absence of agonist.

The concentration-response relationship for membrane currents was converted into units of $P$ \{open\} (Fig. 3C) as described in the Materials and Methods. From fitting the curve to eq. 4 , with $\mathrm{L}_{\mathrm{WT}}$ set to 9000 and $\mathrm{N}_{\mathrm{GABA}}$ to 2 , we obtained a $K_{\mathrm{GABA}}$ of $72 \mu \mathrm{M}$ and $c_{\mathrm{GABA}}$ of 0.0033 . The fitted efficacy measure indicates that GABA binds 300 -fold $\left(c^{-1}\right)$ more tightly to the open than the closed receptor, and that the binding of a GABA molecule contributes $-3.37 \mathrm{kcal} / \mathrm{mol}$ of free energy to stabilization of the open state.

Changing $L$ by Allosteric Potentiators or Gain-ofFunction Mutations Alters the $\mathbf{E C}_{50}$ for GABA in a Predictable Way. We examined the relationship between the $\mathrm{EC}_{50}$ for GABA and the value for $\mathrm{L}$. We altered $\mathrm{L}$ by addition of the allosteric drugs propofol, alfaxalone, or pentobarbital. Figure $4 \mathrm{~A}$ shows the log-log plot of measured $\mathrm{EC}_{50}$ for GABA against the $L$ value for wild-type $\beta \alpha \gamma+\beta \alpha$ receptors for activity elicited by GABA in the absence or presence of the three allosteric agonists: propofol at concentrations of 5, 10, and $20 \mu \mathrm{M}$; pentobarbital at concentrations of 100 and $200 \mu \mathrm{M}$; and alfaxalone at $1 \mu \mathrm{M}$.

The presence of the allosteric agonists shifts the value for $\mathrm{L}$ up to 1000-fold from the value for $\mathrm{L}$ in the absence of drugs. The corresponding shift in the observed $\mathrm{EC}_{50}$ for GABA is well described by the measured change in L coupled with the parameters estimated for activation by GABA $\left(c_{\mathrm{GABA}}\right.$ and $\left.K_{\mathrm{GABA}}\right)$ in the absence of any drugs. That is, no information about the properties of the combination of drugs was used in predicting the relationship. The slope of a linear regression of $\log \left(\mathrm{EC}_{50}\right)$ on $\log (L)$ is $0.63 \pm 0.05$ (mean \pm S.E.M.). This is greater than $1 / N_{\mathrm{GABA}}(1 / 2)$ but not statistically significantly so $(P=0.06$ by a two-tailed $t$ test $)$.

We also altered L by mutation of the receptor. Figure 4B shows data for receptors containing the $\alpha 1(\mathrm{~L} 263 \mathrm{~S})$ and/or $\beta 2(\mathrm{Y} 143 \mathrm{~W})$ mutation. Both mutations have been reported to enhance constitutive activity in the $\mathrm{GABA}_{\mathrm{A}}$ receptor without altering $K_{\mathrm{GABA}}$ (Chang et al., 1996; Chang and Weiss, 1999; Eaton et al., 2016). Introduction of the mutation in either construct shifted the value for $\mathrm{L}$, indicating that both concatemers incorporated in the receptor. The shifts in $\mathrm{EC}_{50}$ with the different $L$ values are close to the predicted values and scatter around the regression for the data for the relationship between $\mathrm{EC}_{50}$ and $\mathrm{L}$ seen in Fig. 4A. Furthermore, the shift in GABA $\mathrm{EC}_{50}$ for a mutant receptor $(\beta(\mathrm{Y} 143 \mathrm{~W}) \alpha \gamma+\beta \alpha)$ in the presence of a background drug (propofol) is close to the predicted value. The slope of a linear regression $\log \left(\mathrm{EC}_{50}\right)$ on $\log (\mathrm{L})$ is $0.60 \pm 0.11$, which did not differ from the slope for wild-type $\beta \alpha \gamma+\beta \alpha$ receptors shown in Fig. 4A. Accordingly, changes in basal activity by mutation or addition of a background agonist can have similar effects on the $\mathrm{EC}_{50}$ for activation by GABA (Table 2).

Changing $N_{\mathrm{GABA}}$ : Effect of the $\beta 2(\mathrm{Y} 205 \mathrm{~S})$ Mutation on Activation by GABA. Previous work found that the $\beta 2$ (Y205S) mutation greatly increases $\mathrm{EC}_{50, \mathrm{GABA}}$ (Amin and Weiss, 1993; Baumann et al., 2003), effectively removing the GABA-binding site. If placed in a single $\beta 2$ subunit it should therefore reduce the value of $N_{\mathrm{GABA}}$ from 2 to 1 . We expressed receptors composed of the $\beta \alpha \gamma$ concatemer and the $\beta(\mathrm{Y} 205 \mathrm{~S}) \alpha$ concatemer, and we determined the $\mathrm{EC}_{50}$ values for GABA in the absence and presence of propofol or the $\alpha(\mathrm{L} 263 \mathrm{~S})$ mutation.

The results are shown in Fig. 5. The solid line shows the predicted values for the $\mathrm{EC}_{50}$ assuming that values obtained for the wild-type receptor apply $\left(\mathrm{L}_{\mathrm{WT}}=9000, K_{\mathrm{GABA}}=72 \mu \mathrm{M}\right.$, and $c_{\mathrm{GABA}}=0.0033$ ), while $N_{\mathrm{GABA}}=1$. The predicted curve, with no free parameters, goes remarkably close to the data. 

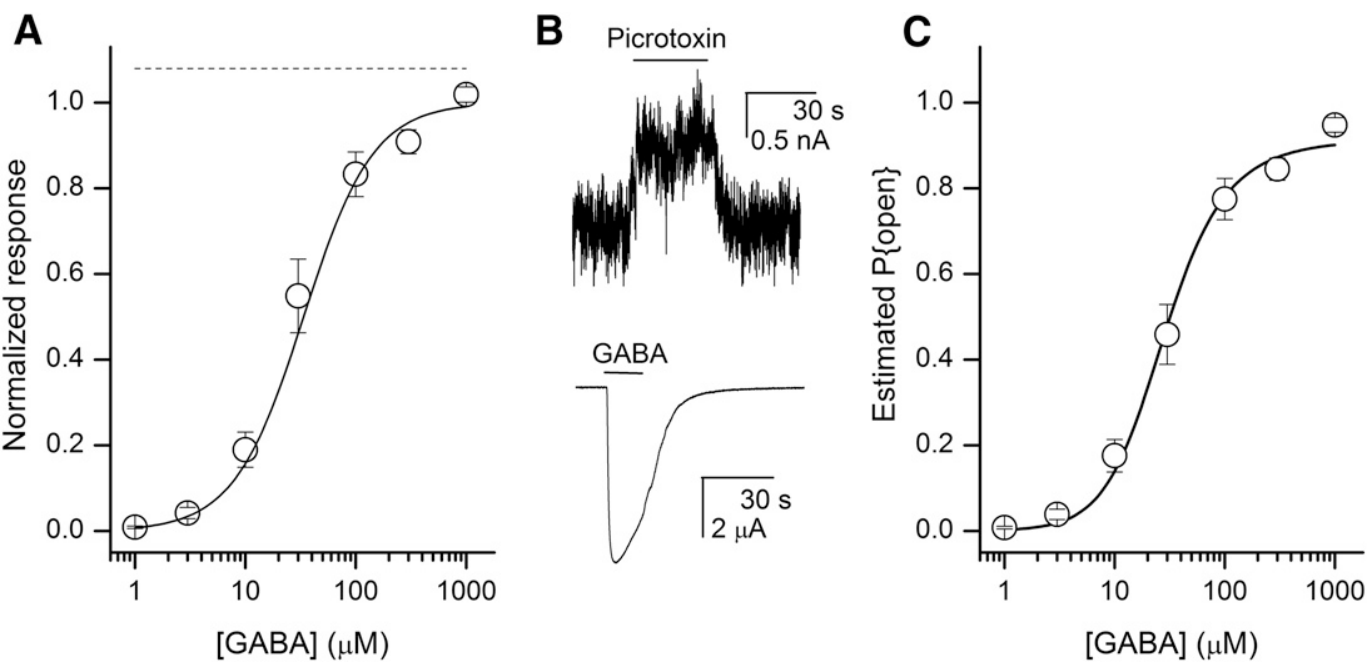

Fig. 3. Properties of the wild-type $\beta \alpha \gamma+\beta \alpha$ concatemeric receptor. (A) Mean current responses elicited by GABA $(O)$ normalized to the maximal fitted response. The line shows predictions of eq. 1 to the data. The mean values of the fit were $\mathrm{EC}_{50, \mathrm{GABA}}=34 \pm 8 \mu \mathrm{M}$ and $n_{\mathrm{H}, \mathrm{GABA}}=1.38 \pm 0.07(n=5$ cells). $(\mathrm{B})$ Responses to $300 \mu \mathrm{M}$ picrotoxin and $1000 \mu \mathrm{M}$ GABA. The current traces are from the same cell. (C) Concentration-response data expressed as the estimated probability of being open plotted against the agonist concentration. The lines show the predictions of the MWC model (eq. 4) fitted to the data with the parameters $\mathrm{L}_{\mathrm{WT}}=9000, \mathrm{~N}_{\mathrm{GABA}}=2, K_{\mathrm{GABA}}=72 \pm 15 \mu \mathrm{M}$, and $c_{\mathrm{GABA}}=0.0033 \pm 0.0004$.

The predictions clearly demonstrate that the consequences of a reduced value for $N$ are apparent in the relationship between $\mathrm{EC}_{50}$ and $\mathrm{L}$. Not only is the degree of curvature altered over this range of values for $\mathrm{L}$ but the slope for $\mathrm{L}<$ 500 is increased when $N$ is decreased. The linear regression for $\mathrm{L}<500$, shown by the dashed line in Fig. 5, has a slope of
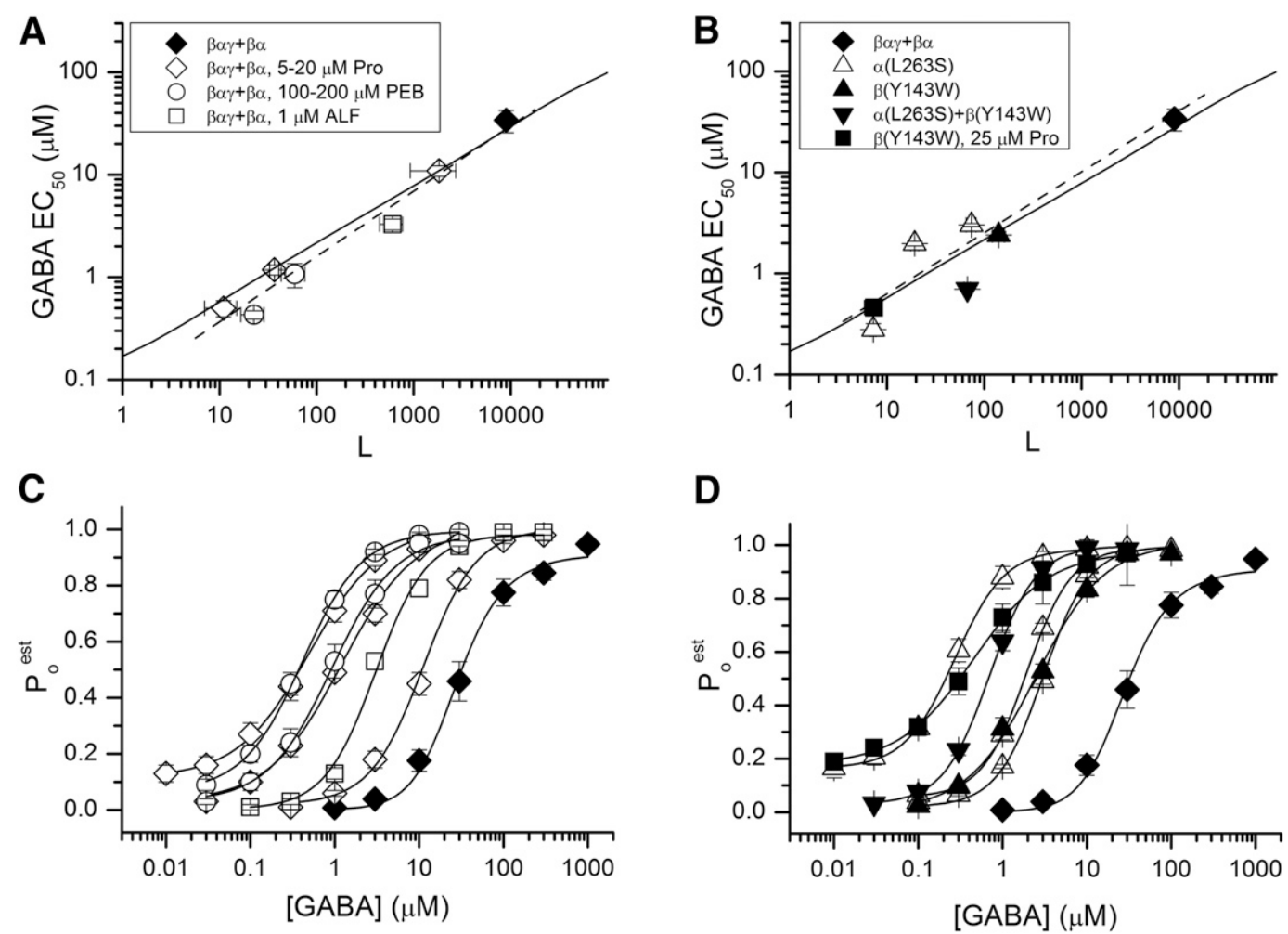

Fig. 4. Effect of change in $\mathrm{L}$ on activation by GABA. The measured $\mathrm{EC}_{50}$ for GABA is plotted logarithmically against the value for L. (A) Data for receptors composed of wild-type concatemers in the absence of any other drug $\left(\mathrm{L}_{\mathrm{WT}} \bullet\right.$ ) or in the presence of propofol $(\diamond$; concentrations of 20,10 , and $5 \mu \mathrm{M}$ from lower to higher L), pentobarbital $(\bigcirc ; 200$ and $100 \mu \mathrm{M})$, or alfaxalone $(\square ; 1 \mu \mathrm{M})$. The symbols show mean values, and the error bars indicate \pm 1 S.E.M. The solid line shows the predicted relationship between the $\mathrm{EC}_{50}$ and $\mathrm{L}$ using the values estimated for the wild-type: $\mathrm{L}_{\mathrm{WT}}=9000, N_{\mathrm{GABA}}=2, K_{\mathrm{GABA}}=72 \mu \mathrm{M}$, and $c_{\mathrm{GABA}}=$ 0.0033 . The dashed line shows the linear regression of $\log \left(\mathrm{EC}_{50}\right)$ on $\log (\mathrm{L})$ (slope $\left.=0.63 \pm 0.05\right)$. (B) Data for receptors containing the $\alpha 1(\mathrm{~L} 263 \mathrm{~S})$ mutation $(\triangle ;$ from lower $\mathrm{L}$ to higher L mutation is in both constructs, in $\beta \alpha \gamma$, or in $\beta \alpha)$, the $\beta 2(\mathrm{Y} 143 \mathrm{~W})$ mutation $(\boldsymbol{\Lambda} ;$ mutation is in both constructs), or the combination of $\beta 2(\mathrm{Y} 143 \mathrm{~W})$ in $\beta \alpha \gamma$ and $\alpha 1$ (L263S) in $\beta \alpha(\boldsymbol{\nabla})$. The plot also shows data for the $\beta(\mathrm{Y} 143 \mathrm{~W}) \alpha \gamma+\beta \alpha$ receptor in the presence of $25 \mu \mathrm{M}$ propofol ( $\mathbf{\square})$. The solid line shows the predicted relationship using the values from fits of data from the wild-type receptor. The dashed line shows the linear regression of $\log \left(\mathrm{EC}_{50}\right)$ on $\log (\mathrm{L})$ (slope $=0.60 \pm 0.11$ ). The data are summarized in Table 2. (C and D) Corresponding concentration-response relationships. The symbols show the mean \pm S.E.M. The symbols are as in graphs $A$ and $B$. The curves show fits to the Hill equation incorporating a low-concentration offset. The $\mathrm{EC}_{50}$ values are given in Table 2 . 
TABLE 2

Experimental observations on $\mathrm{GABA} \mathrm{EC}_{50}$ and $\mathrm{L}$

Values for $\mathrm{EC}_{50, \mathrm{GABA}}$ and $\mathrm{L}$ for the various receptors studied. The first column shows the composition of the receptor, and the second shows the background drug used to modify $\mathrm{L}$. The third shows the $\mathrm{EC}_{50, \mathrm{GABA}}$ and the fourth the value of $\mathrm{L}$. The footnotes indicate how L was determined. Values are mean \pm S.E.M. for data from five or more oocytes.

\begin{tabular}{|c|c|c|c|}
\hline Receptor & Background Drug & $\begin{array}{c}\mathrm{EC}_{50, \mathrm{GABA}} \\
(\mu \mathrm{M})\end{array}$ & Value of $L$ \\
\hline$\beta \alpha \gamma+\beta \alpha$ & None & $34 \pm 8$ & $9000^{a}$ \\
\hline$\beta \alpha \gamma+\beta \alpha$ & $5 \mu \mathrm{M}$ Pro & $11 \pm 1$ & $1826 \pm 904^{b}$ \\
\hline$\beta \alpha \gamma+\beta \alpha$ & $10 \mu \mathrm{M}$ Pro & $1.2 \pm 0.1$ & $37 \pm 4^{c}$ \\
\hline$\beta \alpha \gamma+\beta \alpha$ & $20 \mu \mathrm{M}$ Pro & $0.50 \pm 0.09$ & $11 \pm 4^{c}$ \\
\hline$\beta \alpha \gamma+\beta \alpha$ & $1 \mu \mathrm{M}$ ALF & $3.3 \pm 0.4$ & $606 \pm 161^{c}$ \\
\hline$\beta \alpha \gamma+\beta \alpha$ & $100 \mu \mathrm{M}$ PEB & $1.1 \pm 0.3$ & $59 \pm 16^{c}$ \\
\hline$\beta \alpha \gamma+\beta \alpha$ & $200 \mu \mathrm{M}$ PEB & $0.43 \pm 0.04$ & $23 \pm 6^{c}$ \\
\hline$\beta \alpha \gamma+\beta \alpha(\mathrm{L} 263 \mathrm{~S})$ & None & $3.0 \pm 0.1$ & $74 \pm 9^{a}$ \\
\hline$\beta \alpha(\mathrm{L} 263 \mathrm{~S}) \gamma+\beta \alpha$ & None & $2.0 \pm 0.1$ & $19 \pm 2^{a}$ \\
\hline$\beta \alpha(\mathrm{L} 263 \mathrm{~S}) \gamma+\beta \alpha(\mathrm{L} 263 \mathrm{~S})$ & None & $0.28 \pm 0.04$ & $7.3 \pm 0.4^{a}$ \\
\hline$\beta(\mathrm{Y} 143 \mathrm{~W}) \alpha \gamma+\beta(\mathrm{Y} 143 \mathrm{~W}) \alpha$ & None & $2.4 \pm 0.2$ & $141 \pm 20^{a}$ \\
\hline$\beta(\mathrm{Y} 143 \mathrm{~W}) \alpha \gamma+\beta \alpha(\mathrm{L} 263 \mathrm{~S})$ & None & $0.70 \pm 0.06$ & $67 \pm 5^{a}$ \\
\hline$\beta(\mathrm{Y} 143 \mathrm{~W}) \alpha \gamma+\beta \alpha$ & $25 \mu \mathrm{M}$ Pro & $0.46 \pm 0.06$ & $7.4 \pm 1.5^{c}$ \\
\hline$\beta \alpha \gamma+\beta(\mathrm{Y} 205 \mathrm{~S}) \alpha$ & none & $129 \pm 16$ & $9000^{\bar{d}}$ \\
\hline$\beta \alpha \gamma+\beta(\mathrm{Y} 205 \mathrm{~S}) \alpha$ & $5 \mu \mathrm{M}$ Pro & $88 \pm 9$ & $539 \pm 119^{c}$ \\
\hline$\beta \alpha \gamma+\beta(\mathrm{Y} 205 \mathrm{~S}) \alpha$ & $10 \mu \mathrm{M}$ Pro & $24 \pm 2$ & $315 \pm 58^{c}$ \\
\hline$\beta \alpha \gamma+\beta(\mathrm{Y} 205 \mathrm{~S}) \alpha$ & $20 \mu \mathrm{M}$ Pro & $8.2 \pm 2.0$ & $42 \pm 5^{c}$ \\
\hline$\beta \alpha \gamma+\beta(\mathrm{Y} 205 \mathrm{~S}) \alpha$ & $40 \mu \mathrm{M}$ Pro & $3.9 \pm 0.5$ & $11 \pm 2^{c}$ \\
\hline$\beta \alpha(\mathrm{L} 263 \mathrm{~S}) \gamma+\beta(\mathrm{Y} 205 \mathrm{~S}) \alpha$ & None & $6.1 \pm 1.4$ & $35 \pm 1^{a}$ \\
\hline
\end{tabular}

ALF, alfaxalone; PEB, pentobarbital; Pro, propofol.

${ }^{a}$ Based on the effect of picrotoxin on constitutive activity

${ }^{b}$ Calculated from the current response in the presence of the background drug corrected for constitutive activity.

${ }^{c}$ Calculated from the current response in the presence of the background drug assuming no constitutive activity.

${ }^{d}$ Considered to equal that of the wild-type receptor.

$0.74 \pm 0.1$. The predicted results for the mutated receptor show the asymptotic saturation at high L, supported by the experimental data from the mutant receptors.

Quality of the Description Provided by the Model. The predictions in the preceding experimental section were made using parameters derived from fitting the experimental concentration-response data for wild-type concatemeric receptors activated by GABA (see Fig. 3). The experimental values for $\mathrm{EC}_{50} \mathrm{~s}$ for $\mathrm{GABA}$ were estimated from fitting concentration-response curves. L was estimated from the response to the background drug alone or from inhibition of constitutive activity by picrotoxin. The predictions were then compared with the experimentally determined values for various combinations of drugs or mutations. The agreement is qualitatively acceptable, considering that the predictions covered a range of about 1000 -fold in $\mathrm{L}$ and 100 -fold in $\mathrm{EC}_{50}$. Perhaps the ability to describe the altered relationship between $\mathrm{EC}_{50}$ and $\mathrm{L}$ when the number of transmitter binding sites is altered is most striking, as the only parameter derived from data using the mutated subunit was L.

The first step in applying the model was to extract parameter estimates for activation of wild-type receptors by GABA in the absence of other drugs. In fitting the concentration-response curves we restricted the value for $N$ to integer values, and treated $N$ and $\mathrm{L}$ as constants with $K$ and $c$ as fitting parameters. All the predictions shown in the experimental section were generated with parameters derived using $\mathrm{L}_{\mathrm{WT}}=9000$ and $N_{\mathrm{GABA}}=2$ for the wild-type receptors.

To compare the abilities of different estimates to describe the concentration-response data we also fit with values of $\mathrm{L}_{\mathrm{WT}}=27,000$ and $\mathrm{L}_{\mathrm{WT}}=3000$. These values are near the middle of the range of published values for wild-type $\alpha 1 \beta 2 \gamma 2 \mathrm{~L}$ $\mathrm{GABA}_{\mathrm{A}}$ receptors formed from free subunits $(\mathrm{L}=1000$ 100,000; Chang and Weiss, 1999; Ziemba and Forman, 2016). $N_{\text {GABA }}$ values of 1 to 5 were used. To examine the quality of the description we computed the mean squared difference (MSD) between the fit and the data. Figure 6 shows results for fits of the concentration-response data for GABA. As can be seen, fitting with different values for $L_{W T}$ gave similar MSD values. There is a minimum at $\mathrm{N}_{\mathrm{GABA}}=2$, although an $\mathrm{F}$ test on the variance ratios shows no or minor statistical significance.

It may be surprising that a wide range of values for $\mathrm{L}_{\mathrm{WT}}$ can be used to describe the data for activation of wild-type receptors. This is more understandable when the relationship between the concentration-response data and the model is examined: in the data the two asymptotes are $P$ \{open, basal\} and $\mathrm{P}\{$ open, $\max \}$. The model defines $P$ \{open, basal\} as $1 /(1+\mathrm{L})$ and $\mathrm{P}$ \{open, $\max \}$ as $1 /\left(1+\mathrm{L} c^{\mathrm{N}}\right)$. When $P$ \{open, basal\} is very low then both $\mathrm{L}$ and $c$ are determined largely by $\mathrm{P}\{$ open, $\max \}$, and for a given $P$ \{open, $\max$ \} pairs of $\mathrm{L}$ and $c$ are possible as long as $\mathrm{L} c^{\mathrm{N}}=\mathrm{L}^{\prime} c^{\prime \mathrm{N}}$. For example, fitting the wild-type data with eq. 4 for activation by GABA with $N_{\mathrm{GABA}}=2$ and $\mathrm{L}_{\mathrm{WT}}=$ 27,000 gave a value for $c_{\mathrm{GABA}}$ of $0.0019(P\{$ open, $\max \}=0.91)$, while $\mathrm{L}_{\mathrm{WT}}=9000$ gave $c_{\mathrm{GABA}}=0.0033(0.91)$ and $\mathrm{L}_{\mathrm{WT}}=$ 3000 gave $c_{\mathrm{GABA}}=0.0056(0.91)$. These findings are in agreement with previous theoretical studies on the relationships between constitutive activity and MWC parameters (Ehlert, 2014a). Similarly, the value for $N$ can vary. Again, if L is set then pairs of values for $c$ and $N$ are possible provided $c^{\prime N^{\prime}}=c^{N}$. However, the value for $N$ is additionally constrained by the shape of the concentration-response curve, as indicated by the fact that different values of $N$ affect the MSD to a larger extent (Fig. 6).

Different values for $\mathrm{L}_{\mathrm{WT}}$ and $N$ result in altered relationships between $\mathrm{EC}_{50}$ and $\mathrm{L}$. To assess the ability of the parameters to describe the relationship between $\mathrm{EC}_{50}$ and $\mathrm{L}$ we predicted the $\mathrm{EC}_{50}$ values for data for the data in Fig. 4, A and $B$ (wild-type receptors in the absence or presence of background drugs and receptors containing mutations). 


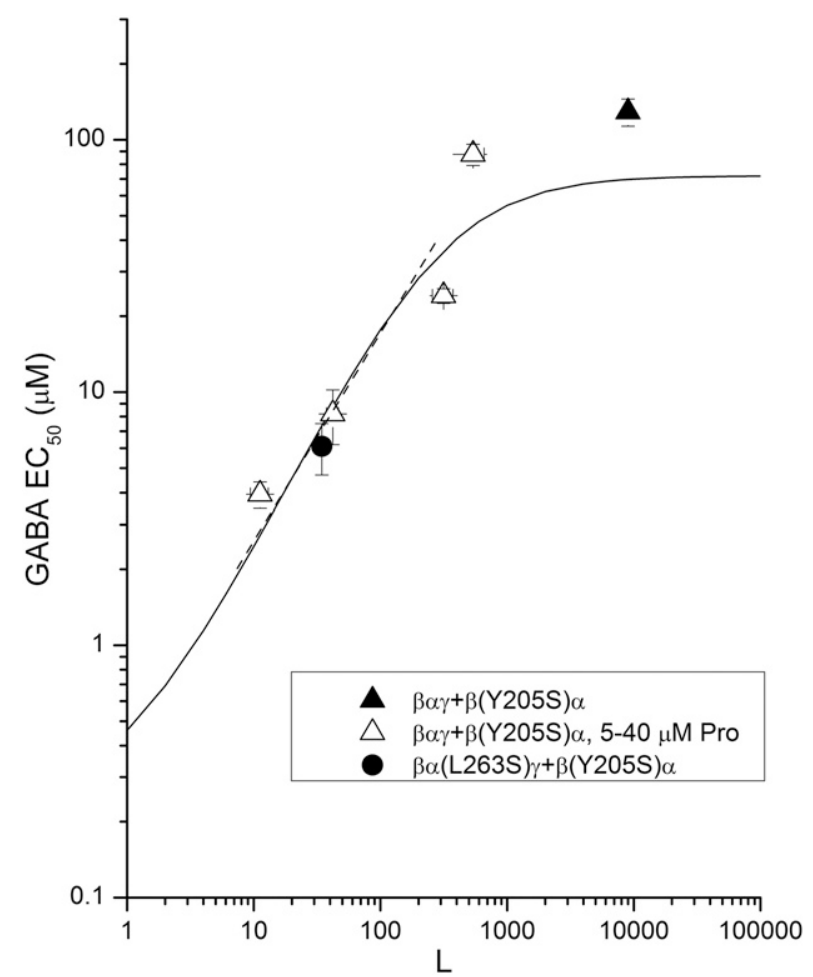

Fig. 5. Effect of change in $N_{\mathrm{GABA}}$ on activation by GABA. The figure shows data for receptors composed of a $\beta \alpha \gamma$ concatemer and a $\beta(\mathrm{Y} 205 \mathrm{~S}) \alpha$ concatemer in the absence of propofol $(\boldsymbol{\Lambda})$ and in the presence of four different concentrations of propofol $(\triangle ; 40,20,10$, and $5 \mu \mathrm{M}$ from lower to higher L). The filled circle shows data from a receptor containing two mutations: $\beta \alpha(\mathrm{L} 263 \mathrm{~S}) \gamma$ and $\beta(\mathrm{Y} 205 \mathrm{~S}) \alpha$. The solid line shows the predicted values for the $\mathrm{EC}_{50}$ assuming that $\mathrm{L}_{\mathrm{WT}}=9000, K_{\mathrm{GABA}}=72 \mu \mathrm{M}$, and $c_{\mathrm{GABA}}=$ 0.0033 (unchanged from wild-type receptor values), while $N_{\mathrm{GABA}}=1$. The dashed line shows the logarithmic regression from the linear region of the predicted line $($ slope $=0.74 \pm 0.1$ ).

The wild-type receptor concentration-response data were fitted with eq. 4 using different assumed values for $\mathrm{L}_{\mathrm{WT}}(3000,9000$, or $27,000)$ and $N_{\mathrm{GABA}}(1,2$, or 3$)$ to obtain estimates for $\mathrm{K}_{\mathrm{GABA}}$ and $c_{\mathrm{GABA}}$. These parameters were used to predict the relationship between $\mathrm{EC}_{50, \mathrm{GABA}}$ and $\mathrm{L}$ (Fig. 7). The differing values for $\mathrm{L}_{\mathrm{WT}}$ shifted the predicted values along the abscissa (Fig. 7A), whereas a change in $N_{\mathrm{GABA}}$ led to a change in slope (Fig. 7B).

We then computed the error from the logarithms of the ratio of the experimental to the predicted $\mathrm{EC}_{50}$ values, to reduce the consequences of the large range in observed $\mathrm{EC}_{50}$ values that would skew the simple squared difference estimate. Figure 7, $\mathrm{C}-\mathrm{D}$ show the ratio $\mathrm{EC}_{50 \text {,exp }} / \mathrm{EC}_{50 \text {,pred }}$ plotted logarithmically against $\mathrm{L}$. The calculations indicate that an $\mathrm{L}_{\mathrm{WT}}$ of 9000 and $\mathrm{N}_{\mathrm{GABA}}$ of 2 provide predictions that are relatively close to the observed $\mathrm{EC}_{50}$.

The results of a statistical analysis of the data are shown in Table 3. Inspection of the table indicates that for wild-type $\beta \alpha \gamma+\beta \alpha$ the closest description of those tested was obtained with $\mathrm{L}_{\mathrm{WT}}=9000$ and $\mathrm{N}_{\mathrm{GABA}}=2$, as also suggested by inspection of Fig. 7.

Overall these analyses indicate that it can be difficult to accurately estimate the activation parameters from concentration-response curves alone, especially when basal activity is low. However the relationship between $\mathrm{EC}_{50}$ and $\mathrm{L}$ can allow us to determine whether some values provide better descriptions than others.

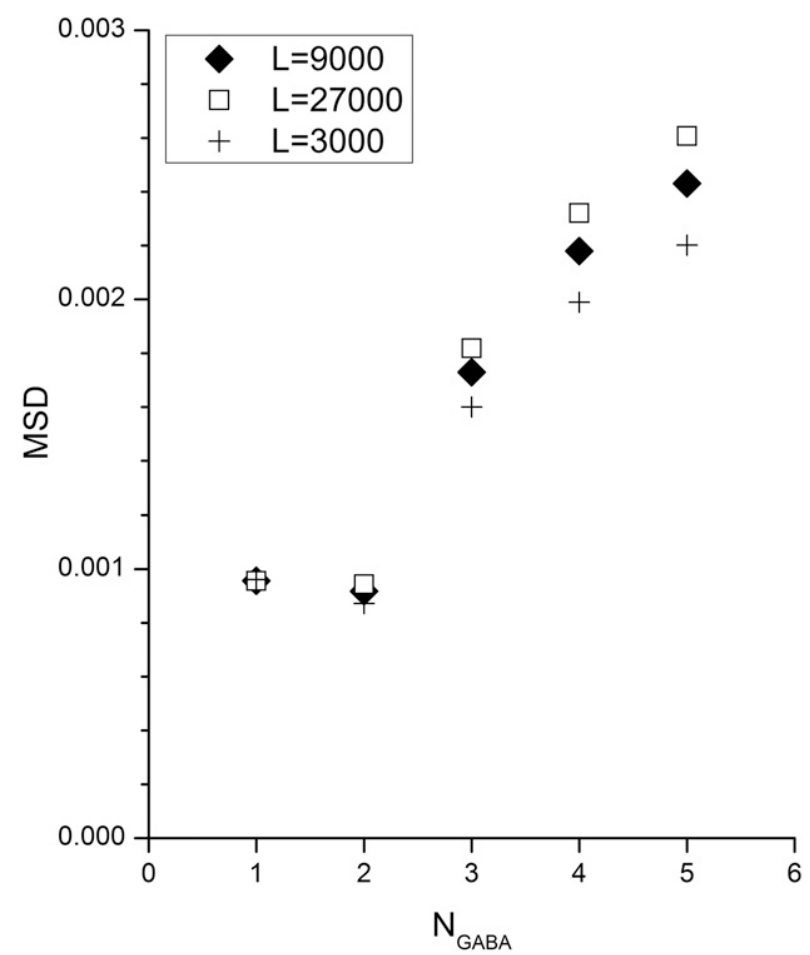

Fig. 6. Quality of description of concentration-response data with different assumed values for $\mathrm{L}_{\mathrm{WT}}$ and $N_{\mathrm{GABA}}$. The mean squared differences (MSD) between the predicted and measured concentration-response data are shown for different values of $\mathrm{L}_{\mathrm{WT}}$ and $N_{\mathrm{GABA}}$. The concentrationresponse data (see Fig. 3B) were fit with various values for $N_{\mathrm{GABA}}$ as indicated on the abscissa and three values for $\mathrm{L}_{\mathrm{WT}}(9000 \bullet, 27,000 \square$, and $3000+)$. An F test on the ratio of MSD values indicated that the difference between $N_{\mathrm{GABA}}=2$ and $N_{\mathrm{GABA}}=4$ or 5 was marginally statistically significant $(P<0.04$ for all $\mathrm{L}$ values, uncorrected for multiple comparisons).

\section{Discussion}

The results in this study indicate that the concerted transition model is able to accurately predict the relationship between the $\mathrm{EC}_{50}$ for activation by GABA and basal activity. The agreement is remarkable considering that the parameters for activation by GABA were established by analysis of a single data set: the concentration-response relationship for GABA acting on wild-type $\beta \alpha \gamma+\beta \alpha$ receptors in the absence of any other GABAergic agent. We perturbed the system by altering $\mathrm{L}_{\mathrm{WT}}$ by addition of a background drug or introducing a gain-offunction mutation. We altered $N_{\mathrm{GABA}}$ (the number of binding sites for GABA) by mutation. For all cases, the new relationship between $\mathrm{EC}_{50}$ and $\mathrm{L}$ was predictable by the model.

It is particularly interesting that predicting the effects of a combination of drugs (e.g., propofol as the background drug in combination with GABA) did not require any data from experiments involving the combination; the effect of the background drug was assessed from modified L measured in the absence of GABA while the activation parameters for GABA were obtained in the absence of the background drug. Removal of one GABA-binding site produced the expected changes in the relationship between $\mathrm{EC}_{50}$ and $\mathrm{L}$ for a change in $N_{\mathrm{GABA}}$ from 2 to 1 , as would be expected from the ample data supporting the idea that the wild-type receptor has two transmitter binding sites (Amin and Weiss, 1993; Baumann et al., 2003). 
A

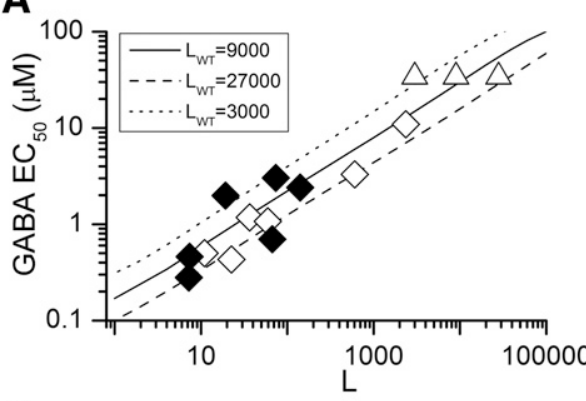

C

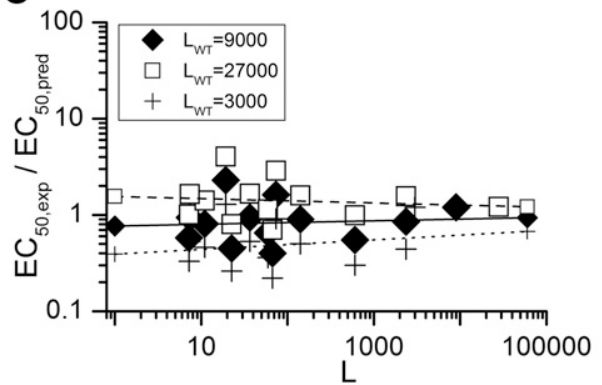

B

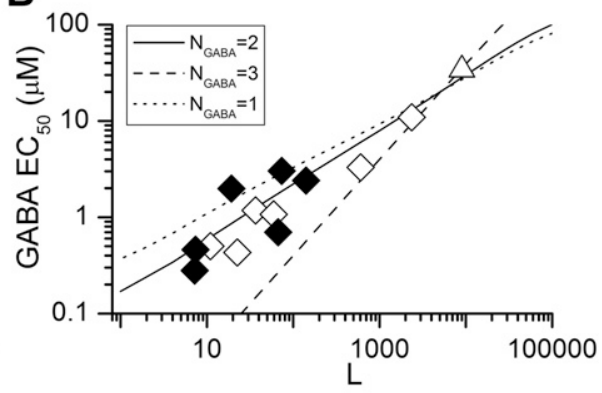

D

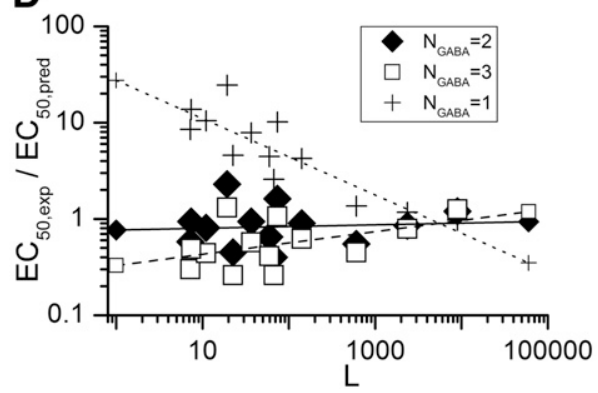

Fig. 7. Predictions of $\mathrm{EC}_{50}$ values made using parameters generated with different values for $\mathrm{L}$ and $N$. (A and $\mathrm{B}$ ) Data for $\mathrm{EC}_{50, \mathrm{GABA}}$ and $\mathrm{L}$ replotted from Fig. 4, A and B. (A) Lines show the predicted relationships for three different assumed values of $\mathrm{L}_{\mathrm{WT}}$ with $N_{\mathrm{GABA}}=2$. (B) Lines show predicted relationships for three assumed values for $N_{\mathrm{GABA}}$ with $\mathrm{L}_{\mathrm{WT}}=9000 .(\triangle)$ Data for wild-type receptors in the absence of other agonists; note that $\triangle \triangle \triangle$ are shown in $A$, corresponding to the assumed values for $\mathrm{L}_{\mathrm{WT}} .(\diamond)$ Values in the presence of a background drug. ( $\left.\diamond\right)$ Values in the presence of an $\alpha 1(\mathrm{~L} 263 \mathrm{~S})$ mutation. (C and D) Quality of the descriptions assessed by calculating the ratio of the experimental $\mathrm{EC}_{50, \mathrm{GABA}}$ to the predicted $\mathrm{EC}_{50, \mathrm{GABA}}$, which is plotted against L. (C) Data when the value of $\mathrm{L}_{\mathrm{WT}}$ was changed while $N_{\mathrm{GABA}}=2$. (D) Changes in $N_{\mathrm{GABA}}$ with $\mathrm{L}_{\mathrm{WT}}=9000$.The lines identified by the symbols at the ends of the lines show the linear regression of $\log ($ ratio $)$ on $\log (\mathrm{L})$. Comparison of $(\mathrm{A}-\mathrm{C})$ indicates that an $\mathrm{L}_{\mathrm{WT}}$ value of $3000\left(N_{\mathrm{GABA}}=2\right)$ provides predictions that consistently lie above the observed values (ratio $<1$ ), for $\mathrm{L}_{\mathrm{WT}}=27,000$ consistently lie below, and for $\mathrm{L}_{\mathrm{WT}}=9000$ are relatively close to the observed $\mathrm{EC}_{50}$. Similarly, the predictions for $N_{\mathrm{GABA}}=1$ or 3 (B and D) demonstrate increasing large inaccuracies relative to the experimental $\mathrm{EC}_{50}$ values as L departs further from the value for wild-type receptors in the absence of agonists, while the predictions for $N_{\mathrm{GABA}}=2$ have a relatively constant relationship to the observed $\mathrm{EC}_{50}$. The results are summarized in Table 3.

The predicted $\mathrm{EC}_{50, \mathrm{GABA}}$ values for receptors containing the gain-of-function $\alpha 1(\mathrm{~L} 263 \mathrm{~S})$ or $\beta 2(\mathrm{Y} 143 \mathrm{~W})$ mutations were calculated using the value for basal activity (L) from the mutant receptor and the estimate for affinity to the transmitter $\left(K_{\mathrm{GABA}}\right)$ in the wild-type receptor. Similarities in the predicted and experimental $\mathrm{EC}_{50, \mathrm{GABA}}$ indicated that the effects of the mutations could be accounted for by assuming that the mutations modified $L$ with no effect on $K_{\mathrm{GABA}}$. There is no a priori reason to expect that a mutation that affects receptor activation by the transmitter acts indirectly, solely through changes in basal activity. These two mutations were selected based on prior reports that had indicated minimal

\section{TABLE 3}

Quality of description with different values for $N$ and $\mathrm{L}_{\mathrm{WT}}$

The experimental values for $\mathrm{EC}_{50}$ for GABA were compared with values predicted with different assumed values for $N_{\mathrm{GABA}}$ and $\mathrm{L}_{\mathrm{WT}}$ using the logarithm of the ratio $\left(\mathrm{EC}_{50 \text {,exp }} / \mathrm{EC}_{50 \text {,pred }}\right)$ to assess the quality. The first and second columns give the assumed value for $\mathrm{L}_{\mathrm{WT}}$ and $N_{\mathrm{GABA}}$. The third column gives mean \pm S.E.M. for the parameter. The fourth column gives the $P$ value that the mean differs significantly from 0 (where a value of 0 indicates identity of $\mathrm{EC}_{50, \exp }$ and $\mathrm{EC}_{50 \text {,pred; }}$ one sample two-tailed $t$ test). The data sets analyzed are shown in Fig. 4, A and B, 13 pairs of values for $\mathrm{L}$ and $\mathrm{EC}_{50, \mathrm{GABA}}$.

\begin{tabular}{lccc}
\hline \multicolumn{1}{c}{$\mathrm{L}_{\mathrm{WT}}$} & $N_{\mathrm{GABA}}$ & $\log \left(\mathrm{EC}_{50, \mathrm{exp}} / \mathrm{EC}_{50, \text { pred }}\right)$ & $P$ to 0 \\
\hline 3000 & 2 & $-0.32 \pm 0.07$ & 0.001 \\
9000 & 2 & $-0.08 \pm 0.06$ & 0.22 \\
27,000 & 2 & $0.15 \pm 0.06$ & 0.04 \\
9000 & 1 & $0.69 \pm 0.13$ & $<0.001$ \\
9000 & 2 & $-0.08 \pm 0.06$ & 0.22 \\
9000 & 3 & $-0.26 \pm 0.07$ & 0.005 \\
\hline
\end{tabular}

effect on $K_{\mathrm{GABA}}$ (Chang and Weiss, 1999; Eaton et al., 2016). Mutations that additionally modify $K_{\mathrm{GABA}}$ would be expected to exhibit deviations from the predicted, model-based relationship between $\mathrm{EC}_{50}$ and $\mathrm{L}$. Therefore, compliance with the predicted relationship can serve as indicator of the mechanism of action for a mutation.

The $\mathrm{GABA}_{\mathrm{A}}$ receptor is a target for many drugs, including sedatives, tranquilizers, and anesthetics. These drugs can both directly activate the receptor and potentiate the responses to GABA. It will be quite useful if our present results can be extended to more complex combinations of drugs, as the use of the MWC model greatly simplifies the task of characterizing the properties of combinations of drugs.

The particular kinetic model we used is a simplified version of a cyclic model, in which thermodynamic cycles are closed. A cyclic model was first proposed to underlie aspects of transmitter-gated channel function in the context of desensitization of nicotinic receptors (Katz and Thesleff, 1957). The particular scheme we used simplified a cyclic model significantly. The basic assumption is that the receptor exists in only two states: active (open channel) and inactive (closed channel), in varying degrees of ligation. That is, there are no intervening states in which the rate constants for one or another transition depend on the degree of ligation of the receptor (e.g., association of drug $\mathrm{A}$ in the absence of bound drug $\mathrm{B}$ versus in the presence of bound drug B).

This assumption reduces the number of free parameters greatly, as can be seen when the model is compared with a full allosteric model (e.g., the "binary elements" model used by 
Goldschen-Ohm et al., 2014). The two-state assumption also leads to the idea that the receptor undergoes the gating transition as a unit-all subunits undergo a concerted transition because otherwise a variety of combinations of subunits in various conformational states would ensue. The second assumption is that all sites for a given ligand are identical. The concerted nature of the activation necessitates that the sites change affinity (if they do at all) in a concerted fashion when the receptor as a whole changes state between active and inactive.

These assumptions result in the kinetic scheme shown in Fig. 1. Many alternative possible schemes exist, as laid out initially by Koshland et al. (1966). In terms of full cyclic schemes, MWC analyses have been applied to $\mathrm{GABA}_{\mathrm{A}}$ (Chang and Weiss, 1999; Rüsch et al., 2004; Ruesch et al., 2012) and muscle nicotinic (Jackson, 1989; Auerbach, 2012) receptors. Partially cyclic schemes ("flip" and "prime") have been used for data from glycine (Burzomato et al., 2004; Plested et al., 2007) and nicotinic receptors (Lape et al., 2008; Mukhtasimova et al., 2016). Finally, a "binary element" analysis has been applied to studies of $\mathrm{GABA}_{\mathrm{A}}$ receptors, which allows for all possible pairwise interactions between functional elements in a receptor (Goldschen-Ohm et al., 2014).

The peak responses studied here are pseudo steady-state measurements, reflecting both open and brief duration desensitized states while slow desensitization is explicitly excluded from the two-state cyclic model we used. Desensitization of the $\mathrm{GABA}_{\mathrm{A}}$ receptor is not fully understood, but it seems likely that there are at least two phases distinguishable by kinetics-a faster and a slower phase (Jones and Westbrook, 1995; Steinbach and Akk, 2001; Bianchi and Macdonald, 2002). In terms of single-channel kinetics, a cluster at high [GABA] has a mean duration of 2 to 3 seconds (Akk et al., 2001), producing slow desensitization that would be observed in oocyte recordings. There are also intracluster closed time components that have been associated with receptor desensitization (Haas and Macdonald, 1999; Steinbach and Akk, 2001; Lema and Auerbach, 2006). In single-channel activity from concatemeric $\mathrm{GABA}_{\mathrm{A}}$ receptors these closed states have mean durations ranging from 0.5 to 25 milliseconds (Akk et al., 2009). Our simulations (not shown) indicate that omission of these states in the model (Fig. 1) has a relatively small effect (less than $10 \%$ ) on the estimated open probability of the peak response and the predicted $\mathrm{EC}_{50}$. We did not analyze responses at the overall steady state, reflecting long-lived desensitization.

The major strength of the MWC model is its simplicity. There is no pairwise specific interaction among agents; all interactions are mediated through the overall energy available to activate the receptor. The fact that the scheme consists of closed cycles means that at equilibrium the state function for a single agonist can be fully described with only four parameters. The energetic contribution of an agonist is defined in a single parameter $(c)$ scaled by the number of sites for the agent $(N)$. Activation is enhanced by the increased affinity of drug for its sites in the open state, reflected in the stabilization energy $\Delta \mathrm{G}_{\mathrm{A}}=\mathrm{N}_{\mathrm{A}} \mathrm{RT} \times\left(\ln \left(\left(1+[\mathrm{A}] / \mathrm{K}_{\mathrm{A}}\right) /(1+[\mathrm{A}] /\right.\right.$ $\left.\left(c_{\mathrm{A}} \mathrm{K}_{\mathrm{A}}\right)\right)$ ), which offsets the free energy difference between the unliganded closed and open states, $\Delta \mathrm{G}_{\text {int }}=\mathrm{RT} \ln (\mathrm{L})$. Interactions between drugs are predicted to occur because the application of a background drug reduces the free energy difference to be overcome by agonist $A\left[\Delta \mathrm{G}_{\text {int }+\mathrm{B}}=\mathrm{RT} \ln (\mathrm{L})+\Delta \mathrm{G}_{\mathrm{B}}\right]$ rather than as a result of a change in any of the parameters for activation by $\mathrm{A}$.
The three drugs used to potentiate the responses to GABA (propofol, pentobarbital, and alfaxalone) produced similar shifts in the $\mathrm{EC}_{50}$ for GABA for similar shifts in L. These drugs belong to chemically distinct classes of anesthetics and have distinct (although possibly overlapping) binding sites on the receptor (Jayakar et al., 2014). The observation that they produce similar shifts gives circumstantial and modelindependent support to the idea that the shifts reflect a nonspecific effect on receptor activation. Our analysis does not address the validity of the MWC model as a detailed description of activation of the $\mathrm{GABA}_{\mathrm{A}}$ receptor by a single agonist, but rather explores the mechanism by which interactions between the transmitter and an allosteric agonist might take place. Although the MWC model has been shown to be able to describe the macroscopic activation of GABA receptors and interactions between several anesthetics and GABA (Chang and Weiss, 1999; Rüsch et al., 2004; Ruesch et al., 2012), it is not clear that it is as successful at accounting for responses to combinations of diazepam with GABA (Gielen et al., 2012; Goldschen-Ohm et al., 2014; however, see Rüsch and Forman, 2005; Campo-Soria et al., 2006). In particular, there may be a requirement for an additional activated-butclosed state between inactive and active open (Gielen et al., 2012; Goldschen-Ohm et al., 2014).

We have emphasized the ability of the model to predict the relationship between $\mathrm{EC}_{50}$ and $\mathrm{L}$. However the predictions are not exact; there is some scatter of observed values around the predicted line. The reasons for this disagreement are not known at present. One clear possibility is the presence of variability in the experimental values. Other possibilities are that the MWC model is overly restrictive in its assumptionsfor example that there are no specific interactions among drugs or that conformational changes are strictly concerted.

\section{Authorship Contributions}

Participated in research design: Akk, Steinbach.

Conducted experiments: Shin, Germann.

Performed data analysis: Akk, Shin, Germann, Steinbach.

Wrote or contributed to the writing of the manuscript: Akk, Shin, Germann, Steinbach.

\section{References}

Akk G, Bracamontes J, and Steinbach JH (2001) Pregnenolone sulfate block of GABA( ${ }_{\mathrm{A}}$ ) receptors: mechanism and involvement of a residue in the M2 region of the $\alpha$ subunit. $J$ Physiol 532:673-684.

Akk G, Li P, Bracamontes J, and Steinbach JH (2009) Activation and modulation of concatemeric GABA-A receptors expressed in human embryonic kidney cells. Mol Pharmacol 75:1400-1411.

Amin J and Weiss DS (1993) $\mathrm{GABA}_{\mathrm{A}}$ receptor needs two homologous domains of the $\beta$-subunit for activation by GABA but not by pentobarbital. Nature 366:565-569. Auerbach A (2012) Thinking in cycles: MWC is a good model for acetylcholine receptor-channels. J Physiol 590:93-98.

Baumann SW, Baur R, and Sigel E (2002) Forced subunit assembly in $\alpha 1 \beta 2 \gamma 2$ $\mathrm{GABA}_{\mathrm{A}}$ receptors. Insight into the absolute arrangement. $J$ Biol Chem 277: 46020-46025.

Baumann SW, Baur R, and Sigel E (2003) Individual properties of the two functional agonist sites in $\left.\operatorname{GABA}_{\mathrm{A}}\right)$ receptors. $J$ Neurosci 23:11158-11166.

Bianchi MT and Macdonald RL (2002) Slow phases of $\operatorname{GABA}_{\mathrm{A}}$ ) receptor desensitization: structural determinants and possible relevance for synaptic function. J Physiol 544:3-18.

Bracamontes J, McCollum M, Esch C, Li P, Ann J, Steinbach JH, and Akk G (2011) Occupation of either site for the neurosteroid allopregnanolone potentiates the opening of the $\mathrm{GABA}_{\mathrm{A}}$ receptor induced from either transmitter binding site. $\mathrm{Mol}$ Pharmacol 80:79-86.

Bracamontes JR and Steinbach JH (2009) Steroid interaction with a single potentiating site is sufficient to modulate $\mathrm{GABA}_{-\mathrm{A}}$ receptor function. $\mathrm{Mol}$ Pharmacol $\mathbf{7 5}$ : 973-981.

Burzomato V, Beato M, Groot-Kormelink PJ, Colquhoun D, and Sivilotti LG (2004) Single-channel behavior of heteromeric $\alpha 1 \beta$ glycine receptors: an attempt to detect a conformational change before the channel opens. J Neurosci 24:10924-10940.

Campo-Soria C, Chang Y, and Weiss DS (2006) Mechanism of action of benzodiazepines on GABA $_{\mathrm{A}}$ receptors. Br J Pharmacol 148:984-990. 
Chang Y, Wang R, Barot S, and Weiss DS (1996) Stoichiometry of a recombinant GABA $_{\mathrm{A}}$ receptor. $J$ Neurosci 16:5415-5424.

Chang Y and Weiss DS (1999) Allosteric activation mechanism of the $\alpha 1 \beta 2 \gamma 2$ $\gamma$-aminobutyric acid type A receptor revealed by mutation of the conserved M2 leucine. Biophys J 77:2542-2551.

Changeux JP and Edelstein SJ (1998) Allosteric receptors after 30 years. Neuron 21: 959-980.

Del Castillo J and Katz B (1957) Interaction at end-plate receptors between different choline derivatives. Proc $R$ Soc Lond B Biol Sci 146:369-381.

Eaton MM, Germann AL, Arora R, Cao LQ, Gao X, Shin DJ, Wu A, Chiara DC, Cohen JB, Steinbach JH, et al. (2016) Multiple non-equivalent interfaces mediate direct activation of $\mathrm{GABA}_{\mathrm{A}}$ receptors by propofol. Curr Neuropharmacol 14:772-780.

Edelstein SJ and Changeux JP (1996) Allosteric proteins after thirty years: the binding and state functions of the neuronal $\alpha 7$ nicotinic acetylcholine receptors. Experientia 52:1083-1090.

Ehlert FJ (2014a) Affinity and efficacy of orthosteric ligands at ligand-gated ion channels, in Affinity and Efficacy pp 73-160, World Scientific, Singapore.

Ehlert FJ (2014b) Analysis of allosteric interactions at ligand-gated ion channels, in Affinity and Efficacy pp 179-249, World Scientific, Singapore.

Forman SA (2012) Monod-Wyman-Changeux allosteric mechanisms of action and the pharmacology of etomidate. Curr Opin Anaesthesiol 25:411-418.

Forman SA and Stewart D (2012) Mutations in the $\mathrm{GABA}_{\mathrm{A}}$ receptor that mimic the allosteric ligand etomidate. Methods Mol Biol 796:317-333.

Germann AL, Shin DJ, Manion BD, Edge CJ, Smith EH, Franks NP, Evers AS, and Akk G (2016) Activation and modulation of recombinant glycine and GABA receptors by 4-halogenated analogues of propofol. $\mathrm{Br}$ J Pharmacol 173:3110-3120.

Gielen MC, Lumb MJ, and Smart TG (2012) Benzodiazepines modulate GABA $\mathrm{A}$ ceptors by regulating the preactivation step after GABA binding. $J$ Neurosci 32 5707-5715.

Goldschen-Ohm MP, Haroldson A, Jones MV, and Pearce RA (2014) A nonequilibrium binary elements-based kinetic model for benzodiazepine regulation of $\mathrm{GABA}_{\mathrm{A}}$ receptors. J Gen Physiol 144:27-39.

Gupta S, Chakraborty S, Vij R, and Auerbach A (2017) A mechanism for acetylcholine receptor gating based on structure, coupling, phi, and flip. J Gen Physiol 149:85-103.

Haas KF and Macdonald RL (1999) $\mathrm{GABA}_{\mathrm{A}}$ receptor subunit $\gamma 2$ and $\delta$ subtypes confer unique kinetic properties on recombinant $\mathrm{GABA}_{\mathrm{A}}$ receptor currents in mouse fibroblasts. J Physiol 514:27-45.

Hernandez CC, Kong W, Hu N, Zhang Y, Shen W, Jackson L, Liu X, Jiang Y, and Macdonald RL (2017) Altered channel conductance states and gating of $\mathrm{GABA}_{\mathrm{A}}$ receptors by a pore mutation linked to Dravet syndrome. eNeuro 4 ENEURO.0251-16.2017.

Jackson MB (1986) Kinetics of unliganded acetylcholine receptor channel gating. Biophys J 49:663-672.

Jackson MB (1989) Perfection of a synaptic receptor: kinetics and energetics of the acetylcholine receptor. Proc Natl Acad Sci USA 86:2199-2203.
Jayakar SS, Zhou X, Chiara DC, Dostalova Z, Savechenkov PY, Bruzik KS, Dailey WP, Miller KW, Eckenhoff RG, and Cohen JB (2014) Multiple propofolbinding sites in a $\gamma$-aminobutyric acid type $\mathrm{A}$ receptor $\left(\mathrm{GABA}_{\mathrm{A}} \mathrm{R}\right)$ identified using a photoreactive propofol analog. J Biol Chem 289:27456-27468.

Jones MV and Westbrook GL (1995) Desensitized states prolong GABA $_{\mathrm{A}}$ channel responses to brief agonist pulses. Neuron 15:181-191.

Karlin A (1967) On the application of "a plausible model" of allosteric proteins to the receptor for acetylcholine. J Theor Biol 16:306-320.

Katz B and Thesleff S (1957) A study of the desensitization produced by acetylcholine at the motor end-plate. J Physiol 138:63-80.

Koshland DE, Jr, Némethy G, and Filmer D (1966) Comparison of experimental binding data and theoretical models in proteins containing subunits. Biochemistry 5:365-385.

Lape R, Colquhoun D, and Sivilotti LG (2008) On the nature of partial agonism in the nicotinic receptor superfamily. Nature 454:722-727.

Lema GM and Auerbach A (2006) Modes and models of $\left.\mathrm{GABA}_{\mathrm{A}}\right)$ receptor gating. $J$ Physiol 572:183-200.

Monod J, Wyman J, and Changeux JP (1965) On the nature of allosteric transitions: a plausible model. $J$ Mol Biol 12:88-118.

Mukhtasimova N, daCosta CJ, and Sine SM (2016) Improved resolution of single channel dwell times reveals mechanisms of binding, priming, and gating in muscle AChR. J Gen Physiol 148:43-63.

Plested AJ, Groot-Kormelink PJ, Colquhoun D, and Sivilotti LG (2007) Singlechannel study of the spasmodic mutation $\alpha 1 \mathrm{~A} 52 \mathrm{~S}$ in recombinant rat glycine receptors. J Physiol 581:51-73.

Ruesch D, Neumann E, Wulf H, and Forman SA (2012) An allosteric coagonist model for propofol effects on $\alpha 1 \beta 2 \gamma 2 \mathrm{~L} \gamma$-aminobutyric acid type A receptors. Anesthesiology 116:47-55.

Rüsch D and Forman SA (2005) Classic benzodiazepines modulate the open-close equilibrium in $\alpha 1 \beta 2 \gamma 2 \mathrm{~L} \gamma$-aminobutyric acid type A receptors. Anesthesiology 102 : $783-792$.

Rüsch D, Zhong H, and Forman SA (2004) Gating allosterism at a single class of etomidate sites on $\alpha 1 \beta 2 \gamma 2 \mathrm{~L} \mathrm{GABA}_{\mathrm{A}}$ receptors accounts for both direct activation and agonist modulation. $J$ Biol Chem 279:20982-20992.

Steinbach JH and Akk G (2001) Modulation of $\mathrm{GABA}_{\mathrm{A}}$ ) receptor channel gating by pentobarbital. J Physiol 537:715-733.

Ziemba AM and Forman SA (2016) Correction for inhibition leads to an allosteric co-agonist model for pentobarbital modulation and activation of $\alpha 1 \beta 3 \gamma 2 \mathrm{~L} \mathrm{GABA}$ receptors. PLoS One 11:e0154031.

Address correspondence to: Dr. Gustav Akk, Department of Anesthesiology, Washington University School of Medicine, Campus Box 8054, 660 S. Euclid Avenue, St. Louis, MO 63110. E-mail: akk@morpheus.wustl.edu 